\title{
El barroco mexicano visto a distancia
}

\begin{abstract}
por
MARTHA FERNÁNDEZ

s

\section{La arquitectura mexicana de los siglos XVII y xvIII \\ de oaquín Bérchez}

Prólogo de RenéT aylor, M éxico,

Azabache, 1992

El libro que ahora reseño forma parte de la colección Arte N ovohispano, en la cual cada uno de los temas tratados fue encomendado a un autor diferente. Así, el que se refiere a la arquitectura novohispana de los siglos xvir y xviır correspondió elaborarlo al investigador

El libro en cuestión, al igual que todos los que forman parte de la serie, es lujosísimo. Las fotografías son en su mayoría de muy buena calidad y la tipografía clara y

La caja cuadrada evitó el innecesario desperdicio de papel y facilitó el ordenamiento de fotografías y textos. Su formato es propicio para editar libros de lujo y para los lectores resulta cómodo. Por lo tanto, La arquitectura mexicana de los siglos XVII y XVIII, tiene la apariencia de ser un libro apetecible, especialmente si a las virtudes de la edición aunamos lo más importante, el tema que aborda,

todo lo cual asegura el éxito comercial de la edición.

Sin embargo, por desgracia, existe lo que podríamos calificar de discordancia entre el lujo de la edición y el nivel del contenido. Al abrirlo solamente, nos asalta la primera pregunta: ¿a quién va dirigido?, ¿en qué tipo de lector pensó Joaquín Bérchez cuando escribió el texto? En primera instancia, se cree que sus potenciales lectores podrían ser neófitos en el tema; pero el lenguaje que utiliza es tan rimbombante, tan "dominguero", que uno acaba por compadecer a esos supuestos lectores, pues el vocabulario les puede resultar totalmente ininteligible y, con ello, dificultárseles la comprensión del tema.

Para un especialista ese lenguaje no resulta extraño, pero sí exagerado. Confundidos, podrían enfrentar la obra desde su propia perspectiva, pero entonces Joaquín Bérchez tendría que aclarar un sinnúmero de problemas que presenta su texto. El primero y el más obvio es el de su concepción del "ser histórico" de la Nueva España, como lo denomina Edmundo 0 'Gorman, cuyo sentido se encuentra en el criollismo, fenómeno que Bérchez no comprendió, tanto así que sitúa el nacimiento de la "conciencia criolla" a fines del siglo xviI.

En efecto, al hablar concretamente de las "peculiaridades" barrocas del templo de la Congregación de Q uerétaro, Bérchez afirma
\end{abstract} Joaquín Bérchez. bien seleccionada. 
que coincide "con el surgimiento de una naciente conciencia criolla, cada vez más afincada en valores sociales y culturales propios que, sin rechazar los del Viejo M undo, comienza a compaginarlos - en claro sincretismo religioso y cultural- con los del pasado prehispánico" (p. II3; el subrayado es mío). Lo sorprendente es que en su bibliografía aparece citado el importante texto de Edmundo $O^{\prime} G$ orman titulado M editaciones sobre el criollismo, donde claramente se explica que la "conciencia criolla" fue "naciente" en el siglo xvi, o sea un siglo antes de lo que afirma Bérchez, de manera que cuando surge el barroco ya es una realidad, tan fuerte, que afectó a esa manifestación artística y la convirtió en uno de los factores de afirmación de su personalidad.

Ahora bien, no entender el criollismo novohispano, no significa no entender un "tema" de la historia de la N ueva España; es clara y justamente no entender su ser histórico, lo que conlleva la lógica falta de entendimiento de sus manifestaciones culturales, entre ellas, por supuesto, las artísticas, lo cual se encarga de demostrar el propio Bérchez a lo largo de todo su libro.

Una de esas pruebas que con facilidad aporta el texto es la ligereza con la que el autor habla de influencia prehispánica en obras barrocas. Lo hace en el párrafo citado anteriormente y lo hace también al tratar de analizar las yeserías (así, en general), en relación con las cuales afirma que no se puede descartar "en la evolución formal de estas yeserías otros factores como son la influencia de las estampas decorativas flamencas y alemanas o la sugestión de algunas formas de origen precortesiano" (p. 57). Si bien es cierto que una de las discusiones más importantes en torno al arte virreinal de $M$ éxico ha sido la presencia o no de elemen- tos de origen prehispánico en las obras, para no caer en afirmaciones tan generales como la transcrita, que al final no aclaran nada, hubiera sido deseable que Bérchez precisara a qué formas concretas se refería y de cuál cultura "precortesiana" procedían. Por supuesto, también debemos aclarar, en honor a la justicia, que la misma imprecisión existe respecto a la influencia de las estampas "flamencas y alemanas".

La misma falta de comprensión del autor del libro reseñado respecto al arte novohispano se manifiesta al negar la existencia de programas iconográficos en las obras barrocas; al menos así lo afirma explícitamente al referirse a los templos de Santa M aría T onantzintla y de San Francisco Acapetec, de los cuales escribe: "muestran una espesa y fantástica decoración de áspero - y al mismo tiempo deslumbrante- tono naturalista, emancipada de todo rastro manierista o programa teológico" (p. 69). I dea que repite al referirse al templo de San Cristóbal de Puebla: "en una vertiente decorativa, las portadas o bóvedas del interior de la iglesia de San Cristóbal cobran relevancia por la desbordada y tupida trama de tarjas y roleos de impronta naturalista, un ornamento ya emancipado y concebido al servicio de su exclusiva expresión" (pp. IOI-IO2). Lo que quiere decir que aquellas complicadas composiciones tuvieron como único fin llenar espacios, pero sin ningún sentido fuera del ornamental. Lo anterior sorprende, porque en su bibliografía, Bérchez cita obras tan famosas como T onantzintla, de Pedro Rojas, que se ocupa del asunto iconográfico.

Uno de los aspectos que me resultaron más curiosos en el libro, fue su intento por definir el tezontle. Su empeño comienza con la siguiente afirmación: "el arquitecto Cristóbal de M edina V argas en I679, al informar 
de las reparaciones que se han de efectuar en la iglesia y convento de la Concepción de M éxico, aconseja 'macizar de tezontle que Ilaman laja' los campamaniles de las esquinas del templo, aclarándonos de este modo la titubeante nomenclatura - tezontl es palabra náhuatl- que recibió esta piedra" (p. 5o). Aunque esto entra también en el terreno de la interpretación documental, de la que hablaremos más adelante, por ahora conformémonos con aclarar lo siguiente: entre los muchos méritos que en lo personal le concedo al arquitecto Cristóbal de $\mathrm{M}$ edina - muchos de los cuales, por cierto, Joaquín Bérchez le escatima- no está el de haber sido etimologista, de manera que difícilmente don Cristóbal pudo ir más allá de la denominación que sus contemporáneos daban al tezontle, por ser un material liviano.

Por supuesto, el hecho de que para Bérchez no es nada clara la "nomenclatura" de tezontle, salta a la vista con su sola idea de que el vocablo náhuatl sea tezontl, que jamás encontrará en ningún diccionario de aquel idioma. La palabra náhuatl es simplemente tezontli, y sus raíces etimológicas son: tetl que significa piedra y zoneua que quiere decir cabellos, remover, batir para hacer algo mullido, poco firme, que se puede interpretar como esponjoso (Remi Simeón, Dictionnaire de la langue nahuatl ou mexicaine, Grazz, Akademische D ruck-U nd Verlagroustalt, 1973).

Al no comprender el material usado en las edificaciones virreinales, Bérchez tiene dificultad para comprender sus técnicas constructivas, de las que sin embargo habla con toda libertad a lo largo de su libro.

En medio de este panorama Joaquín Bérchez plantea su propia clasificación del desenvolvimiento de la arquitectura novohispana del siglo xvir bajo los siguientes rubros: clasicismo, tardoclasicismo y tardoclasicismo evolucionado (pp. 79-Ios), entre los cuales aparece también el manierismo. Este intento, además de válido, hubiera contribuido al mejor entendimiento de la arquitectura virreinal de M éxico (quizá puntualizando o simplificando las clasificaciones tradicionales) si en vez de concretarse a mencionar esos términos, los hubiera definido. Pero no sólo no es así, sino que él mismo es muy impreciso en la aplicación de tales términos, como puede comprobarse al detenerse en el que más me llama la atención: el "tardoclasicismo evolucionado".

Este término lo emplea en relación con obras en las cuales ya se encuentra incorporada la columna salomónica: en $\mathrm{N}$ ueva España elemento tectónico del arte barroco, pero que Joaquín Bérchez no reconoce ple namente como tal, aunque tampoco rechaza del todo, de manera que con confusión afirma: "exponentes ya de un tardoclasicismo evolucionado, cuyas portadas, como ocurre en los cuerpos altos de las de la catedral [de M éxico], dan cabida a novedades de signo barroco, son las iglesias de San Agustín, de Santa Teresa la Antigua y San Bernardo" (p. 9I), todas en la ciudad de M éxico.

El caso es que Bérchez no tiene muy clara la categoría estilística que podría dar a las obras salomónicas del siglo xvII, como tampoco la tiene para las demás obras de esa centuria, al grado de que afirma: "D onde se alcanza el punto culminante de la decoración manierista, casi excediéndola, es en el segundo cuerpo del claustro de la M erced (1693-1703). El agolpamiento de las puntas de diamante en el intradós de los arcos o el profuso y abierto entrelazado de cintas en los fustes de las columnas parecen una premonición de las libertades de signo barroco que se avecinaban en la arquitectura novohispana" (p. 95). Así vemos que la confusión entre 
manierismo y tardoclasicismo, entre el tardoclasicismo evolucionado y el barroco, entre el manierismo y el barroco, parece irresoluble en este libro.

El siglo xviII, sin embargo, resulta aún más incomprensible en el libro de Bérchez. Por ejemplo, habla de él sin analizar dos de sus fenómenos más importantes: la llustración y la Academia de San Carlos. D e la primera, la única alusión directa de su presencia en la N ueva España es cuando, al referirse al arquitecto Francisco Antonio de Guerrero y T orres, afirma: "hombre de curiosidad ilustrada" (p. 278), y de la Academia, lo único que anota como sus productos en obras concretas son las realizadas por los arquitectos José D amián O rtiz de Castro y $M$ anuel Tolsá en la catedral de M éxico ( $p$. 88). Por lo demás, concluye con una afirmación difícil de ser aceptada: "la fundación de la Real Academia de San Carlos en 1783 y las medidas de control y supervisión arquitectónica emprendidas por sus directores impidieron, por la contundencia de su implantación, la natural decadencia de este proceso arquitectónico" (p. 285), es decir, del barroco.

Con ello acepta la existencia de una "decadencia" en procesos artísticos que no considera históricos. Eso, sin contar con un hecho que debería conocer Bérchez: la arquitectura barroca se siguió practicando a pesar de la Academia de San Carlos, como lo muestran las obras del propio Guerrero y Torres; pero, por si eso fuera poco, el neoclásico novohispano se vio muy contaminado de elementos barrocos, como es fácilmente comprobable al revisar las obras.

En fin, el estudio de la arquitectura novohispana del siglo xviri en el libro de Bérchez, sin Ilustración ni Academia y sin haber comprendido el criollismo novohispano, resulta muy limitado.
Tímidamente llega a calificar a las obras de esa centuria como barrocas. De sus modalidades manifiesta franca preferencia por el estípite y el salomónico, especialmente el "apilastrado", como atinadamente lo llama. Las demás modalidades parecen inexistentes y eso produce nuevas confusiones respecto al arte barroco de la N ueva España. Por ejemplo, al referirse a la portada lateral del templo de la Valenciana de Guanajuato sólo dice que se encuentra "inscrita en un gran arco abocinado de poderosa proyección convexa, presenta también órdenes áticos al bies y placas recortadas en la cornisa de caprichosa traza oblicua" (p. 267). Lo mismo ocurre al hablar del retablo mayor del templo de la Enseñanza de M éxico: "se trata de un retablo concebido en una peculiar estructuración de soportes facetados, como si de comprimidas pilastras se tratara" (p. 283). Ambas descripciones, sin ser falsas, tampoco contextualizan artísticamente las obras, Io que resulta de no conocer o no aceptar un término que define la modalidad barroca a la que pertenecen, anástilo, vocablo acuñado hace ya muchos años por Francisco de la $\mathrm{M}$ aza. D ebo aclarar que si hago resaltar la importancia del nombre de esa modalidad barroca, no es nada más porque en lo personal me parezca válida, sino porque el mismo Bérchez reconoce la importancia de asignar nombres a los fenómenos artísticos, tal como hemos visto. Por supuesto, él podría no estar de acuerdo con el término anástilo, pero sería deseable que en ese caso explicara sus razones.

En los mismos términos podemos referirnos a la última modalidad del barroco mexicano, el neóstilo, término usado por Jorge Alberto M anrique desde i97I. En este caso, sin temor a equivocarme, puedo afirmar que no es el desconocimiento, sino un claro re 
chazo a ese término, rechazo que de nueva cuenta sería muy legítimo siempre que lo fundamentara, pero desafortunadamente no es así. D e hecho, llega a aceptar las ideas de $M$ anrique, en su intento por rechazarlas y lo que es peor, ni siquiera lo cita (problema éste generalizado en el libro y del que hablaremos más adelante). D e este modo, Bérchez escribe:

[...] se puede afirmar que con el arquitecto Francisco Antonio Guerrero y Torres (17271792) se cierra o más bien culmina el ciclo emprendido por la arquitectura novohispana a lo largo del siglo xvir y plenamente desarrollada durante todo el xviII. Su obra, antes que nostal gia actualizada del primer barroco mexicano, última carta del mismo, viene a ser por encima de todo, el alcaloide de la arquitectura más específicamente mexicana. Suma y cifra del proceso arquitectónico novohispano, la arquitectura de Guerrero y Torres asume contundentes premisas barrocas cosmopolitas pero sin perder por ello la singularidad de las constantes morfológicas, compositivas y estructurales gestadas en el suelo mexicano desde el siglo anterior. En su personalidad arquitectónica se aprecia una extrema preocupación por aportar atrevidas soluciones estereotómicas a complejos y tradicionales problemas constructivos, lo que - en algunas obras- se traduce en un auténtico exhibicionismo canteril, pletórico de versátiles monteas [p. 277].

Es decir, que lo que Bérchez reconoce en la obra de Guerrero y Torres (uno de los principales representantes de lo que $M$ anrique denomina neóstilo) son, por una parte, "suma y cifra" de la tradición arquitectónica novohispana y, por otra, capacidad innovadora, ambas cualidades que $M$ anrique atri- buye al neóstilo. Finalmente, el rechazo específico de Bérchez a este término sin entender él mismo por qué lo hace, es la evidente contradicción del primer párrafo: si Francisco Antonio de Guerrero y Torres "culmina el ciclo" de la arquitectura novohispana, ¿cómo es que la modalidad artística que representa no es su "última carta"? C abe recordar que $M$ anrique afirma que el neóstilo es la "última carta del barroco mexicano".

Y así, sin tomar en cuenta los conceptos de otros investigadores, él trata de explicar la utilización sorprendente 0 inesperada de ciertas formas en el barroco novohispano con "órdenes enteros": en el templo de la Profesa, "auténtico orden gótico entero" (p. 154) y en el de San Agustín de Q uerétaro, "peculiar paráfrasis poligonal del orden salomónico entero" (p. 203).

Los hilos conductores del libro que re señamos son dos: en primer lugar, lo que Joaquín Bérchez define como una cultura arquitectónica proclive a conocimientos matemáticos, nacida en el siglo xvir, y una dependencia absoluta de los tratadistas de arquitectura europeos, a los que, sin embargo, N ueva España no llega a asumir plenamente.

Acerca de la cultura arquitectónica dedica Bérchez un capítulo que titula "Cultura arquitectónica seiscentista" (pp. 23-3I), cuyas principales ideas repite a lo largo de todo el libro. Reunir en un capítulo los ingredientes más importantes de esa cultura arquitectónica, relacionada con el medio "científico", como lo llama el autor, no está mal; el problema en realidad radica en hacer parecer como novedoso algo que de hecho es obvio para los investigadores dedicados al arte en general y al arte novohispano en particular. Lo que de esta reunión de información resulta sorprendente es que tan importante 
cultura arquitectónica no haya producido - de acuerdo con la visión de Bérchezningún resultado a lo largo de todo el siglo xviI. Como hemos visto, la arquitectura novohispana, según este autor, no superó el "clasicismo" ni siquiera al incorporar columnas salomónicas.

Según Bérchez, en el siglo xviII trabajosamente se pueden vislumbrar logros de esa cultura, pero él los limita a la abstracción geométrica de los elementos arquitectónicos, de manera que su análisis de la arquitectura dieciochesca se reduce a enlistar los elementos poligonales de los edificios, importantes ciertamente en la arquitectura novohispana - especialmente en la que nosotros conoce mos como barroca- , pero no los únicos.

La fantasía, creación, recreación, imaginación, teatralidad, efectismo, que se manifiestan en cualquier monumento barroco de la N ueva España, para Bérchez carecen de importancia, los considera casi accidentes entorpecedores de la arquitectura que pretende analizar. En otras palabras, no contempla las obras como un todo, sino que se contenta con sustraer formas geometrizantes como si éstas, prístinas, pudieran definir las características del barroco. Tan estorbosos le resultan los elementos decorativos y simbólicos de los edificios, que al referirse a la portada principal de la catedral de Zacatecas se apoya en una cita de Chueca G oitia para concluir que esta obra "carece de invención y novedad arquitectónica, 'lo que sucede... es que está totalmente recubierta de decoración, como si su arquitectura hubiera pasado años bajo las aguas del océano y sus formas se hubieran recubierto de madréporas, conchas y corales, hasta fundir sus líneas bajo una espesa costra de adherencias'" (p. 195).

D e esta manera, descarta la posibilidad de entrar en la discusión de un asunto fun- damental en el desarrollo de la arquitectura mexicana: la relación entre elementos decorativos y formas constructivas generales.

Ahora bien, uno de los ingredientes que conformó la cultura arquitectónica novohispana, según Joaquín Bérchez, fue la presencia de los tratadistas europeos. $Y$ es verdad, nadie ha negado ni podrá negar que la presencia de los tratadistas fue muy importante para nuestra arquitectura virreinal. Lo que Bérchez no se detuvo a analizar fue la forma en que los arquitectos novohispanos hicieron uso de esos tratados. De esta forma, el autor citado intenta buscar una dependencia total de la arquitectura virreinal con los tratados, y cuando esa correspondencia no le resultó tan clara llegó a conclusiones que uno no acaba de saber si son irónicas 0 no, actitud mucho más clara cuando se refiere a la arquitectura dieciochesca. Por ejemplo, al hablar del barroco queretano afirma:

[...] la inventiva y exuberancia decorativa acompañan por igual a estos interiores de iglesias y casas como al mobiliario y los retablos, advirtiéndose un deliberado deseo de alcanzar lo insólito y lo sorprendente, no sin cierta dosis de divertida irreverencia, en la interpretación de trasuntos artísticos un tanto sacralizados - incluidos los derivados de las modernas matemáticas- (los hermes del claustro de San Agustín o los arbotantes de Santa Rosa de Viterbo), algo muy similar al tono de distanciamiento humorístico con que se interpretan los principios oblicuos de un Caramuel en la escalera de la casa de San $M$ ateo Valparaíso de la ciudad de M éxico, de Guerrero y Torres 0 en la ventana romboidal de la iglesia parroquial de Zimapán, de José Casimiro Izaguirre [pp. 202-203; los subrayados son míos]. 
Precisamente a consecuencia de esta ventana romboidal, el arquitecto autor de la iglesia parece que resulta "regañado" por Bérchez cuando éste afirma:

[...] como ocurre con los botareles de Santa Rosa de Viterbo de Q uerétaro, aquí es la ventana romboidal... desplazada oblicuamente, como si de un tragaluz se tratara, de la visión ortogonal del testero de la iglesia, la que concita al máximo interés. Los estípites, los arcos lobulados, los cajeamientos, pasan a un segundo plano ante esta invención antinormativa y de amplio reclamo popular, culta y, a fin de cuentas, representativa de lo que podía lle gar la emulación irónica y divertida, de los artificiosos principios oblicuos, defendidos con tesón por el español Caramuel en la lejana Italia [p. 209; los subrayados son míos].

Pero este tono, que da la impresión de sarcástico hacia el arte novohispano, no se detiene en las obras citadas. Joaquín Bérchez lo generaliza cuando de la observación de los famosos arbotantes de Santa Rosa de Viterbo de Q uerétaro, escribe: "esta tendencia a la caricatura, al guiño, de problemas de estética o mecánica constructiva, en absoluto privativa de esta obra, es reveladora de la dual realidad, popular y, al mismo tiempo, erudita, a la que se dirigía el quehacer arquitectónico novohispano" (p. 208; los subrayados son míos).

Como en esas afirmaciones no desarrolla tampoco la idea de lo festivo como una categoría del barroco novohispano, deja la impresión de ser peyorativas, por lo que queda la sensación de que, para Bérchez, todo lo que se aparta de lo explicitado por los tratadistas europeos es caricatura, guiño, popular, irónico, divertido, humorístico, etcétera, como si le quitara al arte novohispano su derecho a ser auténtico aunque sea diferente al europeo.

En cuanto a la metodología del libro, ésta resulta bastante errática. Las causas se podrían resumir en los siguientes puntos:

I. Salvo contadas excepciones (las necesarias para confirmar la regla) no cita sus fuentes, lo que permitió al autor:

a) $\mathrm{H}$ acer pasar como suyas informaciones de otros investigadores. Aunque este problema se presenta en todo el libro y cada vez que Bérchez hace uso de al guna información, pondré - como reza el proverbio popular- sólo un botón de muestra: todos los datos que se refieren a la construcción de las catedrales de San Luis Potosí (p. 190), Zacatecas (p. 195) y Chihuahua (pp. 197 y 198) proceden de obras de Clara Bargellini como La catedral de Chihuahua y La arquitectura de la plata, que sólo aparecen mencionadas en la bibliografía.

b) Parafrasear ideas de otros autores que convinieron a sus fines, como el ya citado problema del neóstilo, que proceden todas de un texto de Jorge Alberto $M$ anrique: "EI 'neóstilo', la última carta del barroco mexicano." 0 el título de un capítulo del libro reseñado: "Presencia del barroco de vertiente matemática al norte y al sur", que procede del famoso capítulo del libro (ése sí magnífico) de George Kubler y M artín Soria, Art and Architecture in Spain and Portugal and their American Dominions, "Los estilos del norte y del sur", etcétera.

c) D escartar, sin ningún fundamento, datos, ideas y teorías que no convenían a sus fines. Como la ya citada del anástilo de Francisco de la M aza, las teorías sobre las modalidades del barroco de M anuel Toussaint, G eorge Kubler, M anuel G onzález Galván...

2. A lo largo del texto, Joaquín Bérchez muestra una inexplicable falta de rigor acerca 
del manejo de información. No existe el menor intento por analizar y sopesar los da tos que obtuvo, sino que fue empalmándolos unos con otros sin caer en la cuenta de las contradicciones que podían resultar de ello. La enumeración de las noticias que adolecen de este defecto a lo largo del libro sería muy extensa; por lo que me contentaré con algunas que al lector resultan más obvias. Por ejemplo, la que se refiere a la autoría del templo de Santa Teresa la Antigua. En la página 92 afirma: "La documentación que vincula a Cristóbal de M edina Vargas con esta iglesia es sólida", pero en la página I22 parece no estar tan seguro de la "solidez" de la documentación y entonces dice: "obra que se atribuye al arquitecto Cristóbal de M edina $V$ argas." El problema es que en este caso tampoco argumenta nada y el lector confundido acaba por no saber si la obra se atribuye 0 es del arquitecto en cuestión, de suerte que sólo quienes conocemos la documentación respectiva podemos estar seguros de que, en efecto, Cristóbal de M edina fue el autor de este templo.

$M$ ás grave en este sentido es lo relativo a los autores del templo de San Francisco Javier de Tepotzotlán. En la página Iig, el autor escribió que los arquitectos $D$ iego de la Sierra y José Durán "estuvieron activos en la obra de la iglesia de San Francisco Xavier del colegio jesuita de Tepotzotlán, entre los años I689 y 1692. D e la Sierra levantó los arcos torales y D urán realizó el abovedamiento de la iglesia." En la página I36, en cambio, afirma de D iego de la Sierra: "emprendiendo muy joven - contaba veintitrés años de edad - la construcción de la iglesia del noviciado jesuita de Tepotzotlán (1679), la cual dejó construida hasta los arcos torales, momento en que se hizo cargo de ella José Durán." Entre levantar arcos torales y abovedar un templo, y construirlo, existe una gran distancia, de manera que caben las preguntas: ¿qué hicieron por fin Diego de la Sierra y J osé D urán en la iglesia de Tepotzotlán? ¿Fueron los autores de traza y montea?

Este problema que presenta el libro, sube de tono al referirse a la catedral de $\mathrm{M}$ orelia. Cito:

[...] la documentación es imprecisa sobre el verdadero autor de la composición de las fachadas [...] Sabemos por una parte que José M edina, maestro de arquitectura, ensamblador y dorador, vecino de Puebla, contrató a fi-

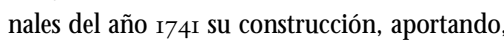
planos y modelos, y que los concluyó en 1746 (la torre poniente ostenta la fecha de 1742 y la fachada la de 1744). Por otro lado, la documentación también nos advierte de la intervención de G erónimo de Balbás en el proyecto de las fachadas, cuando estaba ocupado en la realización del altar mayor o cipres de la catedral de M éxico - en $\mathrm{I}_{742}-$, para lo cual se le concedió permiso para desplazarse a M orelia [p. 20o].

Pero en la página 2oI, más contundente, asegura: "Balbás, ensalzado retablista y criticado arquitecto, artista culto y creativo [...] se pre senta - mientras no haya una documentación más concluyente al respecto- como el candidato más próximo a la concepción compositiva de estas fachadas. 0 tra cosa es que José M edina, del que desconocemos prácticamente todo fuera su ejecutor."

Bérchez obvia sus razones para no considerar "documentación concluyente" el contrato de José de M edina. Pero concedamos que el hecho de firmar un contrato no implica necesariamente la ejecución de la obra (por enfermedad, incumplimiento, etcétera). Entonces nos queda un recurso del 
que podemos echar mano los historiadores del arte: el análisis formal. ¿Podría decirnos Joaquín Bérchez, cuáles son las similitudes formales que encuentra entre la "concepción compositiva" de las portadas de la catedral de M orelia y las obras plenamente documentadas y conocidas de Jerónimo de Balbás?

Por último, una obviedad que podría evitarme, pero que por elemental justicia a José de M edina no lo hago: el hecho de que nosotros, ahora, desconozcamos "prácticamente todo" de él, no es argumento para quitarle autoría al guna.

Para no dejar la misma duda en el lector, debo decir que el asunto de la presencia de Balbás en M orelia, sus proyectos rechazados y el contrato de José de M edina para realizar las portadas y la torre de la catedral, se encuentran satisfactoriamente explicados en el libro titulado La catedral de M orelia, coordinado por N elly Sigaut.

Los enredos de Bérchez con la documentación que llegó a sus manos crecen cuando trata la autoría de la Basílica de Guadalupe. Reproduciré todos los párrafos referentes a ello:

R especto al proyecto de José D urán afirma, con razón, que no fue "Ilevado a la práctica" y continúa:

Por otra parte, D urán y D iego de los Santos fue ron los arquitectos que, en el año de 1694 , comenzaron las obras del santuario Guadalupano 'siguiendo sus trazas y las disposiciones discurridas y que se discurrieron hasta su fenecimiento... y para ello pasaran sus casas y familias a dicho pueblo'. Las trazas a las que se refiere el documento debieron ser con toda probabilidad ya las definitivas. Tradicionalmente atribuida a Pedro de Arrieta, quien personalmente afirmó haberla construido, la Baślica de Guadalupe debe considerarse - en cuanto a idea arquitectónica- obra de José D urán y D iego de los Santos, puesto que este último, en compañía del maestro cantero Feliciano Cabello contrataba al siguiente año [0 sea, I695] las portadas y los pilares del nuevo templo. Arrieta, pues, en fecha que se desconoce, se hizo cargo y culminó en 1709 una obra ya trazada y configurada arquitectónicamente en lo fundamental, aunque no se puede descartar que imprimiese a la obra algún nuevo giro compositivo durante su construcción [p. 135].

[...] Sin ser autor del proyecto de la Baślica de Guadalupe, Arrieta, según propias palabras, fue elegido, en fecha que desconocemos, para trabajar 'por aclamación en la mayor (fábrica) que en ese tiempo se ha ofrecido y que es la de la iglesia de N uestra Señora de Guadalupe', concluyéndola en i709. En la obra iniciada por De los Santos y Cabello y culminada por Arrieta no se abandonó el vanguardismo geométrico [...] [etcétera] la baślica construida por Arrieta se erige en paradigma del potente giro estilístico de la arquitectura mexicana del momento [p. IsI].

Al hablar del templo de La Profesa, escribe: "Como en el templo de Guadalupe realizado por Arrieta" (p. 154).

De entre las numerosas obras que el propio Arrieta afirmó construir... algunos conservan la impronta particular de Arrieta. Tal es el caso del templo de San M iguel, con potentes torres campanarios octogonales muy similares a las de Guadalupe [p. 157].

Sobre el Palacio de la Inquisición: Arrieta "insiste con énfasis en componer los huecos de la puerta y de la ventana con el característico arco semioctogonal que - joven - había construido en Guadalupe" (p. I57). 
I glesia que participa plenamente de las novedades poligonales implícitas en el proyecto y realización de la Baślica de Guadalupe es la del convento de San Francisco de la ciudad de M éxico. Construida nada más concluir aquélla entre I7Io y I7I6, y atribuida a Arrieta, sabemos no obstante, tras los estudios de Eduardo Báez, que fueron D iego de los Santos y Francisco [iFeliciano?] Cabello, quienes dirigieron la obra, los mismos que mancomunadamente emprendieron la construcción de la Baślica [p. I57; los subrayados son míos].

Comencemos por preguntar. Si Bérchez considera que la composición de los vanos de la portada y la planta octogonal de las torres de la basílica son de Pedro de Arrieta:

I. ¿Q ué pasó con el contrato que firmaron en ${ }_{1695}$ Feliciano Cabello y D iego de los Santos?

2. ¿Las torres octogonales no estaban contempladas en el proyecto de José D urán? A esto se tienen que agregar dos contradicciones serias producto de la falta de manejo de las fuentes: en la página I35 afirma que José D urán y D iego de los Santos "comenzaron las obras del santuario G uadalupano", y en la página I27 afirma que fueron $D$ iego de los Santos y Feliciano Cabello quienes "mancomunadamente emprendieron la construcción de la Baślica". En medio de estas dos afirmaciones, aparece que Pedro de Arrieta también construyó la Basílica (pp. I5I y I54).

Es claro que José D urán, D iego de los Santos, Feliciano Cabello y Pedro de Arrieta estuvieron implicados en la construcción del Santuario Guadalupano, lo que resta ahora es que Joaquín Bérchez intente distinguir el trabajo concreto que cada uno realizó en esa obra.

3. En el libro, Joaquín Bérchez muestra también muy poca claridad para establecer la relación entre las noticias que se tienen de una obra y sus características formales. Verbigracia, cuando se refiere al seminario construido en la ciudad de M éxico, posee el dato de que Simón de Castro y Diego Rodríguez fueron los "autores" del antiguo Seminario de la ciudad de M éxico (p. I20).

Lo que no se comprende es qué le hace pensar a Bérchez que la obra de C astro y Rodríguez sea la misma que él describe a partir de una fotografía que reproduce en la página I20. ¿Cuáles características de esa obra reconoce Bérchez de la arquitectura novohispana seiscentista? D e esa interpretación formal Ilega, además, a la dudosa conclusión general de que "durante los últimos años del siglo xvir y las primeras décadas del siglo xviII, lo salomónico evoluciona en su versión apilastrada" (p. I22). ¿Cuáles obras del "salomónico apilastrado" del siglo xviI conoce Bérchez en la N ueva España?

4. El manejo cronológico de la historia tampoco es muy claro en la obra que reseño, pues tenemos que los arquitectos "que preludian el Barroco novohispano" poseyeron "una formación aún anclada en el sólido tardoclasicismo mexicano seiscentista, la cual, en torno a los años ochenta del siglo y en diversa medida, se flexibiliza en unos casos, en otros se abre decididamente a novedades de signo barroco auspiciadas en buena medida por un clima cultural propicio a entender la arquitectura dentro del universo matemático".

Y continúa: "entre los años I690 y I740 una segunda generación de arquitectos [...] consolida en sus obras esta vertiente barroca con una clara conciencia de su especificidad arquitectónica y novohispana. Aunque la ciudad y valle de M éxico junto a Puebla y su entorno son los lugares donde se produce una mayor incidencia de esta peculiar eclosión barroca." 
Todo esto lo dice en una misma página, la II3, y entonces uno reflexiona y pregunta: ¿la primera generación de arquitectos tuvo sólo diez años de vida: 1680-169o?, ¿la conciencia de "especificidad" novohispana madura tan rápido como para haber nacido a fines del siglo xvir y mostrarse tan clara como para marcar una voluntad artística en i69o? A pesar de ello ¿todavía se puede hablar de "eclosión" barroca en la segunda generación de arquitectos?

5. En el estudio de las obras, Joaquín Bérchez tomó el partido lógico del análisis formal, lo cual hubiera podido resultar muy enriquecedor, si hubiera sido más riguroso.

Tal parece que en algunas de sus descripciones utiliza términos sin tomar en cuenta su significado. Así, por ejemplo, al describir la cúpula de la catedral de M éxico informa que se encuentra "equidistante de la fachada de los pies y del extremo de la capilla de los Reyes en el testero" (p. 86), lo que no es verdad, porque la planta del templo no es de cruz griega sino latina.

Asimismo, en relación con la portada principal del templo de San Cristóbal de Puebla, escribió: "la rotundidad de las estrías onduladas de las columnas" (р. IоI). En esa potada no ondulan sólo las estrías, sino las columnas, y lo curioso es que en la página roo muestra un acercamiento de ellas que - aunque no hubiera conocido el templo personalmente- basta para darse cuenta de ello.

Cuando se refiere a la capilla anexa al sagrario de la catedral de Puebla, me surgió la duda de que conociera el mismo edificio que yo. D ice: "los arcos torales que se intersectan son en realidad arcos trilobulados" (p. I44). Los de la capilla que yo conozco son de medio punto, dobles por cierto.

En cuanto a su cúpula, en la misma página nos dice: "el resultado, con la super- posición aditiva de pechinas - las invertidas en las intersecciones esquinadas de los arcos torales y las auténticas que sirven de apeo al tambor- [...]." Es verdad que lo que se encuentra en la intersección de los arcos torales parecen "pechinas invertidas", pero no lo son; se llaman trompas, en tanto que las que sirven de descanso a la cúpula son las pechinas (en efecto, las "auténticas") y la precisión terminológica es importante porque la función arquitectónica de las trompas y las pe chinas es diferente.

Cuando describe la capilla de Loreto de San Luis Potosí informa que posee "auténticas columnillas salomónicas en la portada" (p. 194). ¿Existen columnas salomónicas que no sean "auténticas"? Supongo que se puede hablar de la existencia de varias tipologías formales de esa clase de columnas. ¿Realizó un análisis de cada una de ellas? En todo caso, ¿cuáles serán las no "auténticas" para Bérchez?

Un libro con tantos problemas metodológicos y conceptuales como el que ahora reseñamos, no podía carecer de errores y éste Ios tiene, muchos y de diferente monta. EI listado de ellos podría conformar un catálogo, por lo que anotaré sólo unos cuantos siguiendo la paginación del libro. En la página 43 el autor afirma: "el arquitecto y maestro mayor de la catedral metropolitana Alonso Pérez de Castañeda construyó en la iglesia del H ospital de Jesús en r6or - de cruz latina y nave cubierta con armadura de tijerala que puede considerarse la primera media naranja sobre pechinas erigida en la ciudad de M éxico, al voltear el espacio de la capilla mayor con un casquete ligeramente semiesférico."

En su bibliografía, Joaquín Bérchez cita el libro de Eduardo Báez titulado El edificio de H ospital de Jesús, en el cual se explica que 
la iglesia del Hospital de Jesús no estaba cubierta sino en la zona del crucero, y ahí la techumbre era de madera; luego, entre 1662 y i668 se cubrió, también de madera, provisionalmente el cuerpo de la iglesia y de I684 a i688 se echó la bóveda de mampostería. Es verdad que se había proyectado un artasón de par y nudillo a principios del siglo xviI, pero nunca se realizó. D e manera que la sencilla cúpula que posee debe corresponder a la época en que se construyó la bóveda de mampostería, es decir, i684-i688.

Acerca de la actual catedral de M éxico, en las páginas 8i y 82 nos informa con toda contundencia lo siguiente: "sabemos que el templo proyectado y comenzado a construir por Claudio de Arciniega en I573, continuando por Diego de Aguilera [...] en I593, y más tarde por Andrés de la Concha [...] hasta I6I2, constaba de una planta rectangular [...] tres naves con capillas colaterales, cimborrio en el crucero, bóvedas a la misma altura y sistema de nevaduras a la gótica."

Entre las muchas confusiones que posee esta descripción, podemos mencionar primero la más obvia: no se sabe si se refiere al proyecto de Arciniega, o al estado constructivo en que se encontraba en 16I2. Como más adelante Bérchez se refiere al proceso de construcción, quiero creer que esta descripción se refiere al proyecto de Arciniega, lo que no lo exime de los errores que tiene. Según el proyecto de Claudio de Arciniega, la catedral de M éxico no tendría cimborrio, como se demuestra del impreso que mandó hacer J uan G ómez de T rasmonte entre I635 y I640, para modificar los pilares del crucero con el objeto de que pudieran cargar la cúpula. En este impreso, que debió conocer Bérchez puesto que lo comenta en el libro, Gómez de Trasmonte dice con claridad que el "primer maestro" de la catedral, es decir
Arciniega, no tenía pensado construir cimborrio. Además, del mismo impreso se desprende que las naves que estarían a la misma altura serían las tres centrales y no estarían cubiertas con bóvedas "y sistema de nevaduras [sic] a la gótica", sino de madera. Las nervaduras se emplearon después de la muerte de Claudio de Arciniega para abovedar al gunas capillas, la sala capitular y la sacristía, pero hasta la intervención de Juan Gómez de Trasmonte y de Juan Serrano se resolvió el sistema de abovedamiento que se emplearía en esas tres naves centrales y en las capillas que aún permanecían sin cubierta.

Al hablar de las obras que se realizaron en el siglo xvir en la construcción de la catedral, comenta en la página 86 que las portadas son "auténticas fachadas-retablo situadas entre los estribos - se remataron también en esos años con gigantescas ménsulas avolutadas de elegante decoración ("hermosas canales' se llaman en los documentos) - [...]." Bérchez, que con seguridad conoce el libro de $M$ anuel T oussaint, La catedral de M éxico y el sagrario metropolitano que cita en su bibliografía, debería saber que esas "gigantescas ménsulas avolutadas" no son del siglo xviI, sino de fines del siglo xviri y que las realizó el arquitecto José D amián O rtiz de Castro, Io que demuestra, de paso, que Bérchez no distinguió el carácter neoclásico de esos elementos.

En relación con el templo de Santa Teresa la Antigua, afirma en la página 92 que fue "fundación de Sor Juana Inés de la Cruz". En realidad, sor Juana no necesitó fundar convento alguno para pasar a la historia, le bastó con ser la extraordinaria escritora que fue. Q uien fundó Santa Teresa la Antigua fue sor Inés de la Cruz.

Al parecer, Joaquín Bérchez tampoco está muy familiarizado con la ubicación de 
algunas de las obras que menciona en su libro. Así por ejemplo en la página 92 afirma que el arquitecto Cristóbal de M edina Vargas fue "autor del primero de los quince M isterios del Rosario - el de la Encarnación- en la Calzada de Guadalupe". N o, los M isterios del Rosario dieron nombre precisamente a la calzada donde se encuentran: la de los M isterios, antes llamada de la Piedra, trazada por los mexicas. Q uizá en determinado momento se le conoció con algún nombre que indicara que era la calzada que comunicaba la ciudad con la Basílica de Guadalupe, pero ahora se llama de los $M$ isterios. La calzada de Guadalupe es paralela a la de los M isterios y su traza es del siglo xx.

En fin, el libro completo es muy difícil de leer por tantos problemas que presenta. Es buena, en cambio, su bibliografía y a ella pueden remitirse los interesados.

Terminaré esta reseña con una reflexión que se desprende del párrafo final del prólogo del Dr. René Taylor. El prestigiado investigador afirma que este libro "abrirá los ojos de muchos mexicanos y otros a dos siglos de logros arquitectónicos tan auténticamente mexicanos como los de cualquier otra época".

Si de algún modo me logró "abrir los ojos" el libro de Joaquín Bérchez, ha sido de sorpresa, al darme cuenta de la ligereza con la que trató al objeto de estudio por él elegido: "la arquitectura mexicana de los siglos xvir y xviII." 